\title{
Wanted: cancer boss
}

\section{The White House is looking for a new head for the National Cancer Institute. What kind of person does it take to run a \$4.8-billion research powerhouse? Nature asked some top cancer researchers for their thoughts.}

\section{Donald McDonald}

University of California, San Francisco

It is much easier to describe the perfect person to be director of the National Cancer Institute (NCI) than to find him or her. That person would need to balance the needs, hopes and challenges of state-of-the-art clinical oncologists with those of basic scientists. The ideal candidate must understand the inner workings of the NCI as the pace-setting institute that it is, but also as one of 27 separate institutes and centres - with competing identities, missions and needs - that make up the National Institutes of Health (NIH). Also, this person will have to address the challenges faced by cancer research, like all biomedical research, with declining funding and the changing political climate.

One approach would be to look for someone within the NIH - someone who recognizes all of these problems yet is not daunted by the financial and political conditions. An example would be the current NCI deputy director, John Niederhuber.

\section{Bert Vogelstein}

\section{Johns Hopkins University School of}

Medicine, Baltimore, Maryland

I would suggest Bill Gates as the new director, for two reasons. First, heis one of the few people who could make up shortfalls in funding. Second, and more seriously, he would bring a business perspective that is sorely needed. The NCI is riddled with old programmes that are viewed almost as entitlements and have hindered past

\section{THE NCI}

\section{AT A GLANCE}

Location: Bethesda, Maryland, with a satellite facility in nearby Frederick.

Budget: $\$ 4.8$ billion annually, making it the largest institute in the National Institutes of Health.

Purpose: Among many others, to conduct leading research into the causes and treatment of cancer. Andrew won Eschenbach, NCl's outgoinghead, has set a goal to eliminate suffering and death from cancer by 2015. Many researchers see this as unrealistic. directors from realizing their visions. These vestiges of the past drastically limit the agency's ability to support novel initiatives and, most importantly, new investigators. Just as a business evaluates each of its products in an effort to maximize profits, each $\mathrm{NCI}$ programme should be subjected to a "zero-based budgeting" analysis based on scientific or dinical productivity and the likely impact on disease.

\section{Mary-Claire King}

\section{University of Washington, Seattle}

In my view, the next NCI director should have direct experience of NCI-funded, extramural research in his or her own lab; experience of translating research into patient care; and knowledge of how the NIH and NCI work. I would begin my list with the current directors of the 39 NCI-designated Comprehensive Cancer Centers. These people are respected, and have worked for cancer patients and researchers for their entire careers.

\section{Waun Ki Hong \\ University of Texas M. D. Anderson \\ Cancer Center, Houston}

The NCI director must have a strong track record as a cancer researcher. This person needs a really strong vision and passion for cancer research. She or he must be an excellent advocate with keen political skills. And they must be highly respected and recognized by their peers in the cancer community. With these qualities in mind, I think any of the following people would make a fine director: Phillip Sharp of the Massachusetts Institute of Technology; Max Wicha of the University of Michigan; Harold Moses at the VanderbiltIngram Cancer Center; and Martin Abeloff at Johns Hopkins University.

\section{Hellmut Augustin \\ University of Freiburg, Germany}

Commenting on an American issue from a European perspective is like interfering in domestic affairs - usually not well appreciated. On second thoughts, it is quite tempting. It should be a strong personality who is well rooted in basic as well as translational oncology research, a scientist with a vision beyond

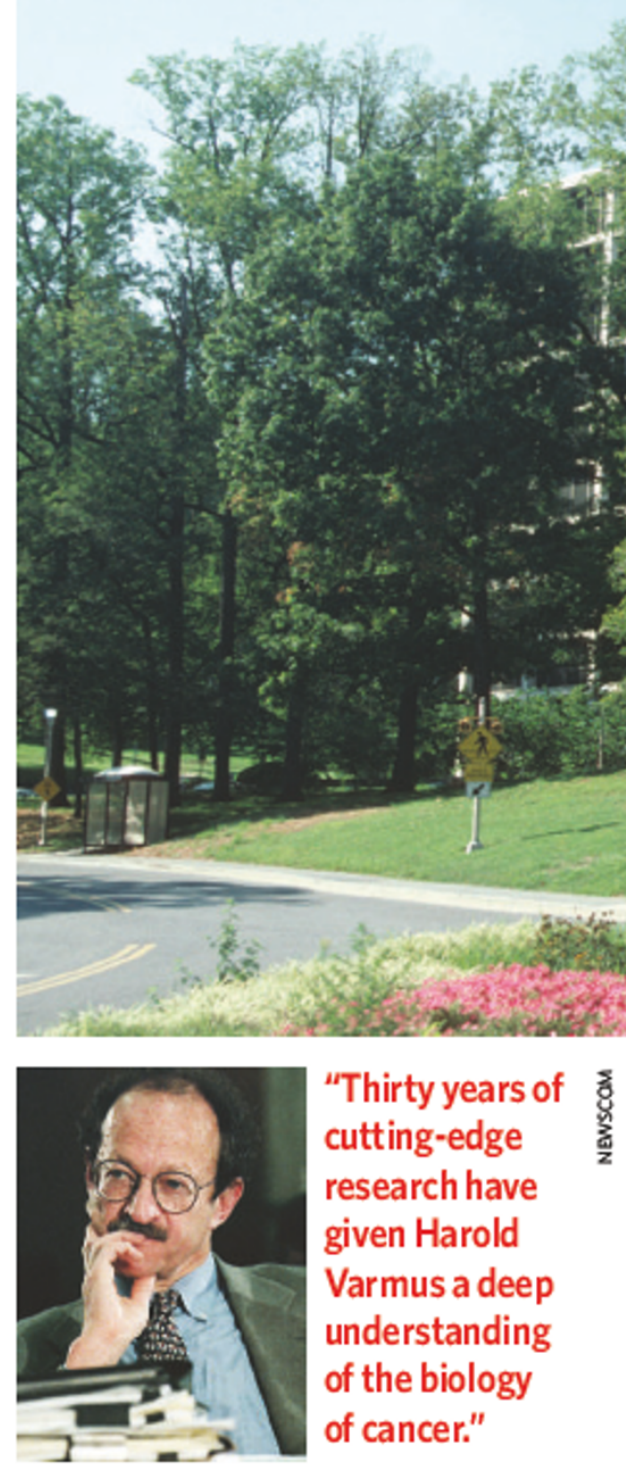

the tumour-cell-centric view, and probably (but not necessarily) an $\mathrm{MD}$ or an $\mathrm{MD} / \mathrm{PhD}$. The job needs someone from outside who can motivate and develop a new corporate identity at the agency, a person of the highest degree of scientific integrity, and an efficient administrator with excellent communication skills. The first person who comes to mind who would fulfil such criteria is Carl-Henrik Heldin at the Ludwig Institute for Cancer Research in Uppsala, Sweden. But why not a female scientist? Margaret Kripke of M. D. Anderson is a member of the President's Cancer Panel. How about a strong basic scientist with an industry background, such as Mark Fishman of the Novartis Institutes for 


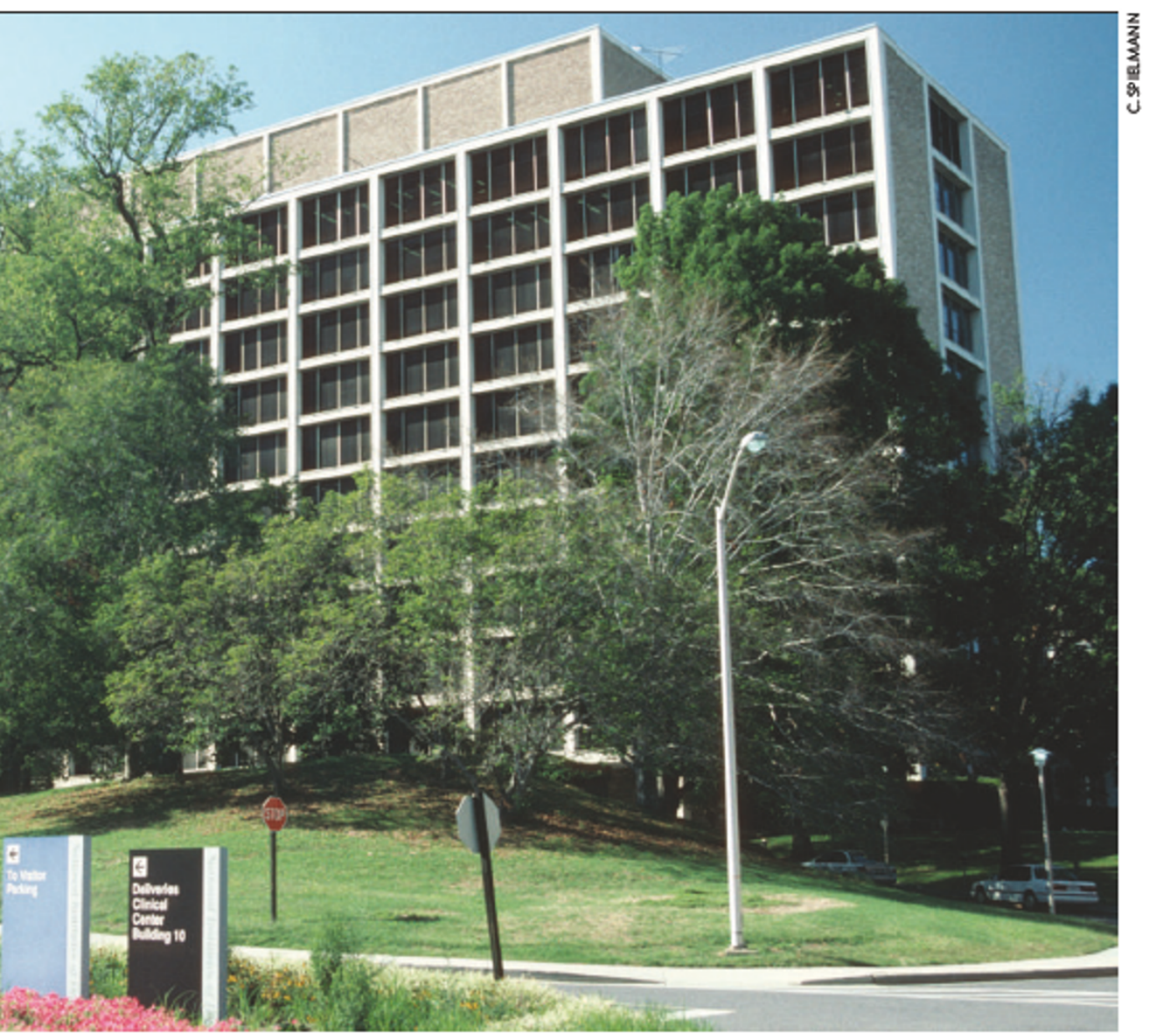

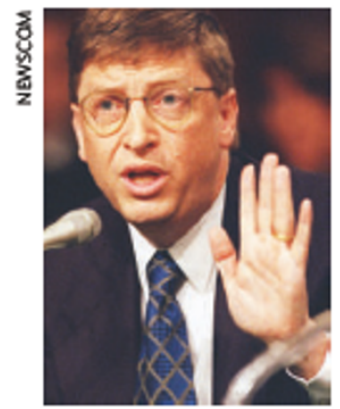

"Bill Gates would bring a business perspective that is sorely needed."

BioMedical Research? Or a bona fide cancer researcher: Bert Vogelstein, Doug Hanahan, Robert Weinberg of the Whitehead Institute or...? Well, a European should probably not interfere in domestic affairs!

\section{Douglas Hanahan}

\section{University of California, San Francisco}

I would choose Harold Varmus, currently president of the Memorial Sloan-Kettering Cancer Center. Thirty years of cutting-edge research have given Varmus a deep understanding of the biology and genetics of cancer. Formerly director of the NIH, he knows about leading a major government agency. Now, as president of Sloan-Kettering, he has assembled an impressive team in basic, translational and clinical cancer research and cancer care, and has recruited world-class scientists and physicians to his institution. This combination of research excellence, grounding in medicine and experience in relevant institutional leadership has uniquely prepared Varmus to guide the NCI and the cancer research community.

\section{Marc Lippman \\ University of Michigan School of Medicine, Ann Arbor}

I think the ideal candidate should be seen by scientists and others in the field as scholarly, original in their thinking, and able to capture the enthusiasm and involvement of the many diverse constituencies that make up the community of people who dedicate their lives to eradicating cancer. Here is an edectic set of names who I think meet all of those criteria: Mina Bissell of the Lawrence Berkeley National Laboratory; Isaiah Fidler of the University of Texas M. D. Anderson Cancer Center; Larry Norton of Memorial Sloan-Kettering Cancer Center; and Philip Pizzo of Stanford University. Interviews by Jacqueline Ruttimann and Meredith Wadman 